\title{
An On-line Lexicographic Tool for Translation
}

Gouri Sankar Mohapatra*

\section{Introduction}

Language is a socio-intellectual aspect of a community, the use of which in education and administration would ensure maximum qualitative and quantitative progress. In this regard, Indian languages fall short of the basic requirements to be effective in the above areas. Language use in India presents peculiar designs, as we find a native language is used for schooling, English in higher studies and a governmental native variety (henceforth GNL) for work at office at there are alternative combinations of these three languages/varieties. The effects of such hazardous set ups are not tangible to assess easily. But minimizing the efforts, energy and time by using a single language (in important areas) will produce greater intelligibility and creativity as it is the nearest (perhaps equal) to one's knowledge faculty.

\section{The Present State of Indian Languages}

A simple investigation of Indian languages in regard to their use reveals that the use of these languages is invariably confined to the day-to-day household life. These backward class of languages are found unsuitable in the areas of education or administration. These are the scheduled languages (SL) enlisted in the constitution are entitled to receive government aids. As a result a new variety of language has emerged which we have already mentioned as GNL. We have reasons to call this variety as the outcome of unplanned and irrational efforts of government.

In the national level and at state levels, government has created various agencies with the aim of large scale "production of terms" in Hindi and other scheduled languages in order to boost their development. These agencies have produced large-scale glossaries in various SLs on Science, Technology and Administration. Now, it

\footnotetext{
* Gouri Sankar Mohapatra teaches Linguistics and Translation in the Dept. of Linguistics, Berhampur University, Orissa.
}

Translation Today Volume (1) No (1) Mar. 2004 (C) CIIL 2004. 
is evident that the terms produced in these glossaries are slowly creeping into the process of translation/transformation of knowledge into Indian languages. A study of these glossaries and their subsequent effect on SLs would force us to assume that Indian languages are going to face a linguistics disaster which would paralyse all of them in every respect. Our assumptions are based on the following facts embodied in the glossaries.

- The terms produced are incompatible with the concerned languages. The incompatibility is both phonological and morphological.

- There is a high degree of contradiction in the use of phonological and morphological subcomponents.

- Careless use of components in compound words which violates syntactic and semantic orders.

- Use of a simple word of target language for more (at times five to six) than one word of the source language.

- Elimination of well accepted nativised borrowed words.

- Indiscriminate use of tautological elements.

It is highly essential now to realize the harmfulness of such glossaries and unqualified "term production agencies" can cause.

\section{Role of translation in developing Indian languages}

Translation will be the most viable mechanism which can bring life back into Indian languages, enable them to keep pace with modern science and technology. To attain this objective translation tools should be designed according to the requirements prevailing in Indian languages at present. To develop one such tool from the scratch we can propose a two-staged development of a lexicographic tool for translators. In the first stage the translators will play a major role in determining the layouts of the elements of such tool minutely. In the second stage these layouts will be further established by a method of convergence which can function as a guiding tool for translators. 


\section{Format of an On-line Lexicographic Tool}

The preparation of an on-line lexicographic tool is to be constructed by a translator or a group of translators on translation.

\section{The Procedure}

\section{Step I}

1. List all the terms / words of the source text in separate spaces.

2. Arrange them alphabetically.

3. Provide each term /word enlisted at (1) with the help of existing dictionaries or existing literature.

4. If (3) is not adequate, then search for the equivalents in the languages related to the target language.

5. If (4) is not adequate, then search for the equivalent in the parent language of the target language.

6. If (5) is not adequate, borrow the term.

\section{Step II}

1. Decompose the semantic components of the terms/words along with citations as work progresses.

2. Do the similar activity with the target equivalents

3. Determine the mismatching cases.

4. Search and find out the required target equivalents for the preceding case.

5. Apply 1-2 to 3 for further enrichment of terminologies.

\section{Step III}

1. Determine synonyms, antonyms, inclusives and exclusives of 3 of step-I.

2. Make necessary changes in 3 of step I.

These interactive modules will be a powerful tool to provide valuable clues in determining the structure of equivalence. We present a diagrammatic form of this procedure as follows: 


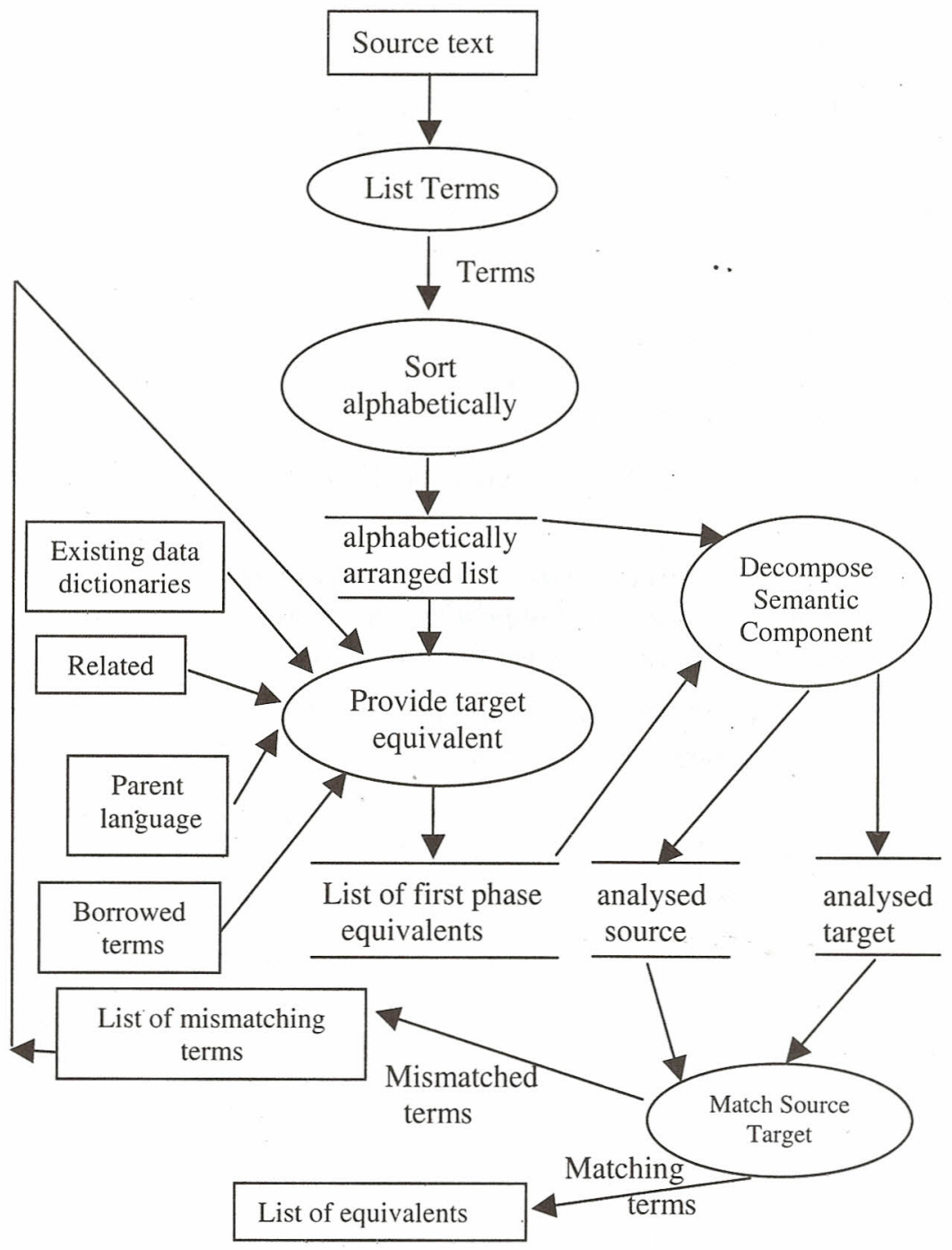

These on-line lexicographic tools should be prepared for various texts pertaining to different subjects. Once this stage is completed, the different on-line lexicographic tools should be converged in the second stage of the process. At this stage a finer relatively stable lexicographic tool can be produced for the purpose of translation and translators. 


\section{Conclusion}

The proposal given above for the development of a translation tool is undoubtedly time consuming. But there are hardly any short cut approaches possible to overcome the problems encountered in the GNL variety.

\section{References}

Frege, Gohlb 1985 On Sense and Meaning (1892) in The Philosophy of Language, ed. Martinich, A.P. Oxford University Press, Inc.

Indian Journal of Applied Linguistics, 1987 vol. XIII, no.1. Bahri Publications.

Nida, Eugene A. 1971 Semantic components in Translation Theory in Applications of Linguistics ed. Perren, G.E. and Trim, J.L.M. Cambridge University Press.

Quine, Willard V. 1964 Meaning and Translation in The Structure of Language, ed. Jerry A Fodor and Jerold. J Katz. New Jersey: Prentice Hall Inc.

Winter, Werner 1968 Impossibilities of Translation in Problems in the Philosophy of Language ed. Olshewsky Thomasm. Holt, Rinehart And Winston. 